OPEN ACCESS

Edited by:

Gao-Xia Wei,

Institute of Psychology - Chinese

Academy of Sciences, China

Reviewed by:

Martin S. Hagger,

Curtin University, Australia

Wolfgang Schlicht,

University of Stuttgart, Germany

Chi Lizhong,

Beijing Sport University, China

${ }^{*}$ Correspondence:

Walid Briki

wbriki@qu.edu.qa

Specialty section:

This article was submitted to Movement Science and Sport

Psychology,

a section of the journal

Frontiers in Psychology

Received: 15 March 2016 Accepted: 22 September 2016

Published: 05 October 2016

Citation:

Briki W (2016) Motivation toward Physical Exercise and Subjective Wellbeing: The Mediating Role of Trait Self-Control. Front. Psychol. 7:1546. doi: 10.3389/fpsyg.2016.01546

\section{Motivation toward Physical Exercise and Subjective Wellbeing: The Mediating Role of Trait Self-Control}

\author{
Walid Briki * \\ Sport Science Program, College of Arts and Sciences, Qatar University, Doha, Qatar
}

Motivation toward physical exercise (MPE) and trait self-control (TSC) were identified as key predictors of subjective wellbeing (SWB). However, there has not been any research designed to examine the mediating role of TSC in the relationship between MPE and SWB. The present study utilizes self-determination theory, control-process theory of self-regulation, and theory of multiple pathways of TSC in order to examine whether TSC mediates the relationships of autonomous MPE (A-MPE), controlled MPE (C-MPE), and impersonal MPE (NO-MPE) with SWB using structural equation modeling (XLSTAT PLS). Three hundred seventeen adult American individuals ( $M_{\text {age }}=32.97, S D_{\text {age }}=11.30$ ), who reported to be regular exercisers, voluntarily answered questionnaires assessing MPE, TSC, and SWB. Correlational analyses revealed positive relationships between A-MPE, TSC, and SWB, and negative relationships of C-MPE and NO-MPE with TSC and SWB. Mediation analyses revealed that TSC mediated the relationships of A-MPE (partial mediation) and C-MPE (full mediation) with SWB, but did not mediate the relationship between NO-MPE and SWB. The estimates of the quality of the hypothesized model were acceptable (outer model GoF $=0.935$; absolute $\mathrm{GoF}=0.330$; relative $\mathrm{GoF}=0.942$; inner model GoF $=1.008 ; R^{2}=36.947 \%$ ). Finally, this study supports the view that MPE can influence SWB through TSC, and incites to pursue the examination of the relationships between self-determined motivation, self-regulation mechanisms, and health-related outcomes.

Keywords: physical activity, self-determined motivation, self-regulation, self-control, psychological health

\section{INTRODUCTION}

Subjective wellbeing (SWB), which can be defined as "...people's evaluations of their lives the degree to which their thoughtful appraisals and affective reactions indicate that their lives are desirable and proceeding well" (Diener et al., 2015, p. 234), represents a growing subject of interest around the world for psychologists, economists, philosophers, and politicians (e.g., Diener, 2000; Diener et al., 2015). Such a phenomenon would reflect the tendency of most societies to recognize the value of the human being and the importance of taking into account self-perceptions for evaluating individual's life (e.g., Diener et al., 2015). Furthermore, the study of SWB lies in positive psychology that corresponds to the scientific study of positive psychological outcomes, psychological health, human capacities, and processes leading to fostering optimal functioning and development (e.g., Peterson and Park, 2003; Peterson and Seligman, 2004). In that perspective, research has found that SWB was a key predictor of health, longevity, moral behavior, and 
performance (e.g., De Neve et al., 2013). For that reason, examining the predictive factors of SWB is of great importance. In addition, such a subject may represent a considerable interest to a worldwide audience.

Research has found that performing physical exercise regularly could promote health and SWB (e.g., Scully et al., 1998; Melzer et al., 2004; Puetz et al., 2006; Sjögren et al., 2006; Meyers, 2008; Biddle and Asare, 2012). Physical exercise represents a leisuretime physical activity, and can be defined as "...cumulative, acute bouts of physical activity that are planned, structured, and repeated and result in improvement or maintenance of one or more components of physical fitness, including cardiorespiratory capacity, muscle strength, body composition, and flexibility" (Puetz et al., 2006). Exercise psychologists have recently examined the relationship between the different types of commitment to exercise - operationalized through the notion of motivation toward physical exercise (MPE) - and SWB (e.g., Sebire et al., 2009; Gillison et al., 2011). Globally, they evidenced that the type of MPE (autonomous vs. controlled) could influence differently SWB. However, the mechanisms underlying such effects are still unclear and require additional investigations (e.g., Standage and Ryan, 2012). Self-control, which can be conceived as the effortful control and effortless (automatic) forms of goaldirected behavior (e.g., Hagger, 2013, 2014), would represent one of the most adaptive variables of the human psyche (e.g., Carver and Scheier, 1998; Tangney et al., 2004) and was found to play a key role in the development of SWB (e.g., Hofmann et al., 2014). Additionally, the type of motivation for goal pursuit appeared to affect the effectiveness of self-control processes (e.g., Milyavskaya et al., 2015). Therefore, the present article aims at examining whether the type of MPE might influence SWB through self-control.

\section{Self-Determined Motivation and Subjective Wellbeing}

Research focused on MPE frequently used the conceptual framework of self-determination theory (e.g., Deci and Ryan, $1985,2000,2008 a, b)$. This theory is grounded in an organismic approach that considers that individuals are, by nature, active, curious, self-motivated, vital, and enthusiastic, even if they may display passivity, laziness, anxiety, or depression symptoms. Interestingly, the theory posits that individuals' positive or negative functioning would result from their interaction with the social environment that either supports or thwarts their deep nature, respectively. Specifically, the theory posits that the human psyche is characterized by three innate needs - i.e., needs for competence (i.e., need of being able to perform well something), relatedness (i.e., need of being connected with others), and autonomy (i.e., need of being at the origin of one's own behavior) that serve the function of developing optimal functioning, performance, and wellbeing. The theory distinguishes three types of functioning: Autonomous, controlled, and impersonal regulations (or motivations).

Autonomous motivation reflects "...a motivational state in which self-initiation and coordination of personally endorsed behaviors predominate" (Weinstein et al., 2011, p. 527). A social environment capable of satisfying the three innate needs is presumed to develop a strong sense of autonomous motivation, which is supposed to be related to optimal functioning, performance, and wellbeing. Intrinsic regulation (i.e., action is based on personal interest and satisfaction), integrated regulation (i.e., action is consistent with different aspects of the self), and identified regulation (i.e., action is personally valued and important) represent forms of autonomous motivation (e.g., Standage and Ryan, 2012). Controlled motivation reflects a “...functioning driven by externally imposed and introjected contingencies, eliciting pressure to conform to perceived expectations" (Weinstein et al., 2011, p. 527). It is assumed that a social environment that is capable of satisfying the needs for competence and relatedness but that thwarts the need for autonomy is presumed to develop a strong sense of controlled motivation. This type of motivation is supposed to be associated with a rigid functioning and a decreased wellbeing. Introjected regulation (i.e., action responds to the desire to avoid guilt and shame or to develop feelings of worth) and external regulation (i.e., action responds to the desire to obtain reward, to avoid punishment, or to meet external expectations) refer to controlled forms of motivation (e.g., Standage and Ryan, 2012). Impersonal motivation (or amotivation), which is associated with poor functioning, passivity and depressed symptoms, develops when the social environment thwarts the three needs (e.g., Standage and Ryan, 2012).

Grounded in the self-determination theory, empirical investigations have reported associations between the different types of motivation and constructs related to SWB (e.g., Gillison et al., 2006; Sebire et al., 2009). Specifically, it was found that autonomous forms of MPE (A-MPE) were positively related to: (a) SWB (measured through a composite construct combining subjective vitality and happiness, $r=0.29$, Sebire et al., 2009), (b) quality of life (measured through a composite construct combining 10 health-related variables, $\beta=0.37$, Gillison et al., 2006), (c) body satisfaction ( $r s=0.28-0.34$, Gillison et al., 2011), and (d) physical self-worth ( $r$ s $=0.24-0.36$, ThøgersenNtoumani and Ntoumanis, 2006; Sebire et al., 2009). Authors also revealed that A-MPE was negatively related to exercise anxiety $(r=-0.33$, Sebire et al., 2009) and social physique anxiety ( $r s=-0.22$ to -0.11 , Thøgersen-Ntoumani and Ntoumanis, 2006; Gillison et al., 2011). In contrast, controlled forms of MPE (C-MPE) and impersonal MPE (NO-MPE) were associated with maladaptive psychological outcomes (e.g., Thøgersen-Ntoumani and Ntoumanis, 2006). Specifically, forms of C-MPE appeared to be positively related or unrelated to social physique anxiety ( $r$ s = 0.10-0.26, Thøgersen-Ntoumani and Ntoumanis, 2006; Gillison et al., 2011). On the other hand, they appeared to be negatively related to body satisfaction $(r=-0.16$, Gillison et al., 2011) and SWB (measured through subjective vitality, $\beta=-0.81$, Edmunds et al., 2006), and negatively related or unrelated to physical self-worth ( $r$ s $=-0.19$ to 0.01 , Thøgersen-Ntoumani and Ntoumanis, 2006). NO-MPE was positively related to social physique anxiety ( $r$ s $=0.18-0.21$, Thøgersen-Ntoumani and Ntoumanis, 2006; Gillison et al., 2011) and negatively related to 
body satisfaction ( $r=-0.19$, Gillison et al., 2011) and physical self-worth $(r=-0.18$, Thøgersen-Ntoumani and Ntoumanis, 2006).

Finally, there is strong evidence that A-MPE (or NOMPE) can promote (or hinder) positive feelings. However, the detrimental effect of C-MPE on positive feelings lacks of consistent evidence in the literature. In the present study, we present some reasons to argue that the relationship between self-determined motivation and positive feelings might be explained, at least partly, by the intervention of self-regulation mechanisms, such as trait self-control (TSC).

\section{Self-Determined Motivation and Trait Self-Control}

Self-regulation reflects self-corrective adjustments that occur to be on track to attain the desired goal (e.g., Carver and Scheier, 1998), and self-control represents a crucial component of this broader phenomenon. Generally, self-control reflects the ability to operate changes in the self so as to develop an optimal adjustment between the self and the world (Tangney et al., 2004). More specifically, self-control can be defined as the capacity of the self to override prepotent responses and to regulate affects, cognitions, and behaviors (e.g., Baumeister and Heatherton, 1996; Tangney et al., 2004; Baumeister et al., 2007). For example, people with high TSC would be better at suppressing one goal (e.g., eating a palatable food) than people with low TSC to pursue another one (e.g., controlling one's weight) that is viewed to have greater importance or utility (e.g., Stroebe et al., 2013). Additionally, authors agree that self-control corresponds to a reservoir of limited resources designed to promote helpful responses (e.g., making plans) and inhibit unhelpful responses (e.g., inhibiting temptations) (e.g., Baumeister and Heatherton, 1996; Muraven, 2008; Hagger, 2013). For example, people with high TSC would have more available resources to self-regulate than people with low TSC.

According to the control-process theory of self-regulation (Carver and Scheier, 1990, 1998), the effectiveness of selfregulation mainly depends upon one's capacity to pursue clear goals. A strong adherence to a specific activity leads to operate a goal selection depending on the degree of relevance and importance of goals for the self. For example, in the case of physical exercise, such a goal selection could consist, on the one hand, in adopting certain goals - such as going to bed early, eating a balanced diet, etc., - and, on the other hand, in eschewing other goals - such as drinking alcohol, smoking, etc. Deci and Ryan (2000) considered that goal-directed activities might differ in the degree to which they are autonomous (i.e., enacted with a full sense of volition and choice) or controlled (i.e., enacted with a full sense of being pressured and controlled). Autonomous activities are consistent with one's integrated sense of self, whereas controlled activities have not been assimilated to the self and, thus, remain external to the self. Accordingly, people who pursue autonomous activities, relative to those who pursue controlled activities, would be more likely to operate a goal selection in accordance with their activity. In that regard, autonomous motivation would be associated with better self-regulation processes than controlled motivation.

Research has revealed that exerting self-control for autonomous reasons was less depleting than exerting selfcontrol for controlled reasons, allowing people to perform better on a subsequent task (Muraven et al., 2007, 2008; Muraven, 2008). Similarly, Moller et al. (2006) found that making choices for autonomous reasons were less depleting and led to better self-control performance than making choices for controlled reasons. This pattern of results suggest that autonomous motivation, relative to controlled motivation, would save more resources for subsequent tasks, thereby leading to maintaining focus on relevant goals. An important implication of such results is that autonomous self-control refers to the identification and integration of values, goals, and behavioral regulations, thereby leading to reinforcing self-control (Deci and Ryan, 1987).

Focusing on mechanisms of self-control, studies have found that autonomous motivation was globally associated with enhanced self-control. More specifically, autonomous motivation appeared to be positively related to TSC ( $r=0.22$, Briki et al., $2015)$ and implementation planning $(r s=0.15-0.31$, Koestner et al., 2008), and positively related or unrelated to automatic attraction toward helpful goals (e.g., healthy foods; $\beta s=-0.05$ to 0.33 , Milyavskaya et al., 2015). However, it appeared to be negatively related to automatic attraction toward temptations (e.g., highly palatable, but unhealthy foods; $\beta$ s $=-0.25$ to -0.17 , Milyavskaya et al., 2015) and perception of encountering obstacles ( $\beta s=-0.25$ to -0.22 , Milyavskaya et al., 2015). Autonomous motivation appeared to be unrelated to controlled attraction toward helpful and unhelpful goals $(\beta s=0.01-0.09$, Milyavskaya et al., 2015) and perception of effort $(\beta=0.03$, Milyavskaya et al., 2015). Using functional magnetic resonance imaging, Lopez et al. (2016) observed positive associations between autonomous motivation, positive mood, and the activity of inferior frontal gyrus - a brain zone reputed to be associated with inhibitory control -, suggesting that autonomous motivation would particularly involve the inhibition of goaldisruptive temptations. Furthermore, controlled motivation was globally unrelated to self-control (e.g., Briki et al., 2015; Milyavskaya et al., 2015). More specifically, it appeared to be unrelated to TSC ( $r$ s $=0.09-0.14$, Briki et al., 2015), implementation planning ( $r$ s $=0.01-0.05$, Koestner et al., 2008), automatic attraction toward helpful and unhelpful goals ( $\beta s=-0.05$ to 0.19 , Milyavskaya et al., 2015), and controlled attraction toward helpful goals ( $\beta=-0.05$, Milyavskaya et al., 2015). However, controlled motivation was found to be positively related to perception of encountering obstacles $(\beta=0.28$, Milyavskaya et al., 2015).

Finally, the set of these studies suggest that autonomous motivation would entail a sense of self-control (e.g., TSC) by inhibiting automatically goal-disruptive impulses and implementing helpful strategies. However, the results reveal unclear relationships between controlled motivation and mechanisms of self-control. 


\section{Trait Self-Control and Subjective Wellbeing}

Does TSC make people happy? A set of studies have provided evidence about the beneficial effects of TSC on positive affect and SWB. The results of De Ridder et al.'s (2012) metaanalysis revealed a positive relationship between TSC and SWB [measured through different types of construct, such as selfesteem, happiness, or absence of depression; $r=0.33$ (number of used studies $=16)$ ]. In the same vein, authors reported that TSC was positively related to SWB (measured through satisfaction with one's life or happiness, $r s=0.24-0.50$, Cheung et al., 2014; Hofmann et al., 2014; Briki et al., 2015), general self-worth ( $r=0.25$, Briki et al., 2015), and positive affect ( $r s=0.27-0.35$, Hofmann et al., 2014; Briki et al., 2015). With a particular focus on the exercise setting, authors showed a positive relationship $(r=0.20)$ between conscientiousness (reflecting the notion of self-control) and positive affective attitude (measured through different constructs, such as enjoyment, interest, and calmness; Rhodes et al., 2002).

Why does TSC make people happy? To answer that question, it is necessary to understand how TSC can predict goal-directed behavior. Drawing from empirical and theoretical work, Hagger $(2013,2014)$ proposed a theory delineating three types of pathway by which TSC influences goal-directed behavior (i.e., direct, indirect, and interactive effects). The first pathway (called "P1") corresponds to a direct relationship between TSC and behavior. For example, people with high TSC are more likely to display goal-directed behavior than people with low TSC. The second and third pathways (called "P2" and "P3") correspond to indirect pathways mediated by motivational components. Specifically, P2 reflects an effect on goal-directed behavior mediated by intention, in the sense that people are more likely to develop intentions to reach a goal that promote, in turn, subsequent goal-directed behavior. P3 corresponds to an effect on goal-directed behavior mediated by impulsive motives, indicating that people are more likely to borrow impulsive route to action in which behavior is controlled by more spontaneous processes. The fourth and fifth pathways (called "P4" and "P5") correspond to two interactive pathways in which TSC (and, especially, available resources) moderates the relationship between motivational components and behavior. Specifically, P4 and P5 represent the processes by which self-control resources influence the conversion of intentions and impulsive motives into action, respectively. In sum, people with high TSC would be not only more likely to develop plans for action in order to attain a self-relevant goal (P2), but also more likely to convert such reasoned decisions into action (P4). In addition, they would be less likely to fall under the control of impulses (P3) and more likely to suppress such impulses (P5).

In line with that theory that predicts that TSC stimulates plans for action and their conversion into action (Hagger, 2013, 2014), authors have demonstrated that TSC could foster happiness and SWB by stimulating effective strategies (Cheung et al., 2014). More specifically, Cheung et al. (2014) revealed a positive relationship between TSC and promotion focus (i.e., motivational orientation concerned with growth, advancement, and accomplishment; $r=0.21$ ), and a negative relationship between TSC and prevention focus (i.e., motivational orientation concerned with vigilance, responsibility, and ought; $r=-0.48$ ). Additionally, they found that both motivational orientations mediated partially the relationship between TSC and happiness, indicating that TSC positively predicted happiness directly and indirectly through increased promotion focus and decreased prevention focus. Furthermore, and consistent with the view that TSC can inhibit goal-disruptive impulses (Hagger, 2013, 2014), authors have revealed that the beneficial effects of TSC on positive affect and SWB might be due to the capability of TSC to manage conflict between competing goals and desires (Hofmann et al., 2012, 2014). More specifically, Hofmann et al. (2014) revealed that TSC was negatively related to problematic desires ( $r s=-0.18$ to -0.20 ; Hofmann et al., 2012, 2014) and that people with high TSC experienced less frequently problematic desires than people with low TSC. Interestingly, Hofmann et al. (2014) also revealed that positive affect (reflecting a momentary psychological state) positively predicted SWB (reflecting satisfaction with life in general), and the authors interpreted this result as the reflection of the tendency of TSC to reinforce consistency within the self, leading to promote positive experiences.

In sum, the set of results suggest that TSC would promote happiness and SWB by activating helpful plans for action and inhibiting problematic desires, leading to increase satisfaction and the likelihood of goal attainment. In that regard, happiness and SWB would be the product of the combination of increased consistency within the self and successful experiences.

\section{The Mediating Role of Trait Self-Control}

McCullough and Willoughby (2009) suppose that TSC represents not only the key variable of self-regulation processes, but also one of the most important mediating variables to account for the relationship between motivation and psychosocial outcomes. Several studies conducted in different domains, such as health, education, and leisure, have evidenced such a hypothesis (e.g., Koestner et al., 2008; Briki et al., 2015; Milyavskaya et al., 2015). More specifically, authors examined the mediating role of self-control components (e.g., implementation planning, automatic attraction toward temptations) in the relationship between self-determined motivation and perceptions of obstacles or goal progress (Koestner et al., 2008; Milyavskaya et al., 2015). They observed that autonomous motivation positively predicted goal progress through increased implementation planning, and that the implementation of approach-oriented plans (i.e., intentions to move toward desired outcomes) strengthened that relationship (moderating effect; Koestner et al., 2008). They also observed that autonomous motivation negatively predicted perception of obstacles through decreased attraction toward goal-disruptive temptations (Milyavskaya et al., 2015), and that controlled motivation negatively predicted goal process through increased perception of obstacles (Milyavskaya et al., 2015). Focusing on wellbeing, Briki et al. (2015) have recently examined the relationships between identified religiosity (reflecting autonomous motivation), introjected religiosity (reflecting controlled motivation), TSC, and SWB. The authors showed that autonomous motivation positively predicted SWB directly 
and indirectly through enhanced TSC. By contrast, TSC did not mediate the relationship between controlled motivation and SWB, supporting previous results showing an independence relationship between controlled motivation and self-control (Koestner et al., 2008; Milyavskaya et al., 2015).

\section{Research Overview}

The present study attempted to examine how MPE, TSC, and SWB might be interrelated, and whether TSC might mediate the relationships of A-MPE and C-MPE with SWB (assessed through the happiness and vitality subscales) in adult regular exercisers. To do so, we built and examined a model using the structural equation model analysis (Figure 1). To assess its quality, different sorts of index were used, such as the goodness-of-fit (GoF) index (e.g., absolute GoF, relative GoF) and the coefficient of determination of the endogenous latent variables $\left(R^{2}\right)$ (e.g., Henseler et al., 2009; Vinzi et al., 2010). The higher the values of GoF indexes and $\mathrm{R}^{2}$, the better the model (see the "Analysis" section below). Based on the tenets of the self-determination theory (e.g., Deci and Ryan, 2000, 2008a,b), the control-process theory of self-regulation (e.g., Carver and Scheier, 1990, 1998; McCullough and Willoughby, 2009), and the theory of multiple pathways of TSC (Hagger, 2013, 2014), and consistent with the above-mentioned studies' results, the present study proposes four sets of hypothesis:

\section{Relationships between MPE and SWB}

In line with previous studies showing that A-MPE (or NO-MPE) was positively (or negatively) related to positive psychological outcomes (e.g., SWB) (e.g., Gillison et al., 2006, 2011; ThøgersenNtoumani and Ntoumanis, 2006; Sebire et al., 2009), we expect A-MPE (or NO-MPE) to be positively (or negatively) related to SWB. However, because research has found that C-MPE was negatively related or unrelated to positive psychological outcomes (e.g., Thøgersen-Ntoumani and Ntoumanis, 2006), we do not

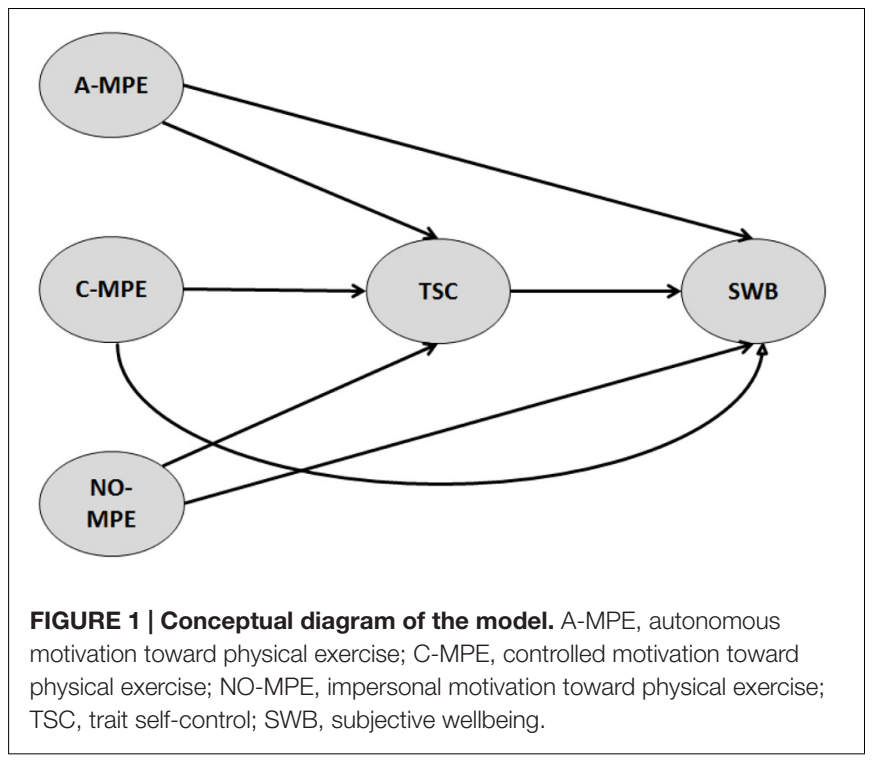

have any prediction concerning the relationship between C-MPE and SWB.

\section{Relationships between MPE and TSC}

Consistent with previous studies showing positive relationships between autonomous motivation and self-control (e.g., Koestner et al., 2008; Briki et al., 2015), we expect A-MPE to be positively related to TSC. However, no clear or consistent evidence allow us to formulate any expectations regarding the relationships between C-MPE and TSC and between NO-MPE and TSC.

\section{Relationship between TSC and SWB}

Because research has found that self-control fostered positive affect and SWB (e.g., Cheung et al., 2014; Hofmann et al., 2014), we expect TSC to be positively related to SWB.

\section{Mediations}

Consistent with previous studies indicating that self-controlrelated-variables (e.g., TSC, implementation planning) might mediate the relationship between autonomous motivation and positive perceptions or feelings (Koestner et al., 2008; Briki et al., 2015), we expect TSC to mediate the relationship between A-MPE and SWB. No consistent evidence allow us to formulate any predictions about the mediating role of TSC in the relationships between C-MPE and SWB and between NO-MPE and SWB.

\section{MATERIALS AND METHODS}

\section{Participants}

Three hundred seventeen adult American volunteers (223 females, 70.3\%, and 94 males, $29.7 \% ; M_{\text {age }}=32.97$, $S D_{\text {age }}=11.30 ; M_{\text {size }}=1.64 \mathrm{~m}, S D_{\text {size }}=0.18 ; M_{\text {weight }}=81.24 \mathrm{~kg}$, $\left.S D_{\text {weight }}=29.14\right)$, who reported to perform physical exercise regularly (e.g., walking, swimming, biking), were recruited from a popular crowdsourcing on-line platform (ClickWorker $\left.{ }^{1}\right)$. On average, the participants reported to perform physical exercise 3.84 times a week $(S D=1.53)$ since 5.70 years $(S D=7.73)$. This sample included participants who were heterogeneous on several qualitative variables, such as socio-demographic variables, (i.e., ethnicity, professional status, familial status), medical variables (i.e., chronic mental and physical disease), and exercise-related variables (i.e., intensity, duration, and mode; Table 1).

\section{Study Design and Procedure}

The present study design was submitted and approved by the ethics committee of Qatar University. Each participant provided his/her informed written consent. The setup of this study included a form that was accessible to participants via a specific web address. This form included general information about the study, a consent form, and questionnaires (see the "Measures" section below). Before answering questions, participants were told that: (a) the survey was designed to examine relationships between physical exercise and feelings, (b) they had to perform physical exercise regularly to participate

\footnotetext{
${ }^{1}$ www.clickworker.com
} 
TABLE 1 | Socio-demography and medical situation of participants, as well as characteristics of their physical exercise.

\begin{tabular}{|c|c|c|}
\hline & $n$ & $\%$ \\
\hline \multicolumn{3}{|l|}{ Socio-demography: } \\
\hline \multicolumn{3}{|l|}{ Ethnicity: } \\
\hline African American & 58 & 18.3 \\
\hline Asian American & 22 & 6.9 \\
\hline Caucasian American & 203 & 64 \\
\hline Hispanic American & 22 & 6.9 \\
\hline Other & 12 & 3.8 \\
\hline \multicolumn{3}{|l|}{ Familial status: } \\
\hline Living in family & 274 & 86.4 \\
\hline \multicolumn{3}{|l|}{ Professional status: } \\
\hline Working & 104 & 32.8 \\
\hline \multicolumn{3}{|l|}{ Medical situation: } \\
\hline \multicolumn{3}{|l|}{ Physical disease: } \\
\hline Having a chronic disease & 40 & 12.6 \\
\hline \multicolumn{3}{|l|}{ Psychological disease: } \\
\hline Having a chronic disease & 42 & 13.2 \\
\hline \multicolumn{3}{|l|}{ Living in wheelchairs: } \\
\hline No & 317 & 100 \\
\hline \multicolumn{3}{|l|}{ Exercise characteristics: } \\
\hline \multicolumn{3}{|l|}{ Duration: } \\
\hline $0-30^{\circ} \mathrm{min}$ & 101 & 31.9 \\
\hline $31-60^{\circ} \min$ & 167 & 52.7 \\
\hline $61-90^{\circ} \mathrm{min}$ & 39 & 12.3 \\
\hline $91-120^{\circ} \mathrm{min}$ & 10 & 3.2 \\
\hline \multicolumn{3}{|l|}{ Mode: } \\
\hline Alone & 199 & 62.8 \\
\hline With friends/partner/family & 81 & 25.6 \\
\hline Within a guided program & 37 & 11.7 \\
\hline \multicolumn{3}{|l|}{ Intensity: } \\
\hline Aerobic exercise & 236 & 74.4 \\
\hline Anaerobic exercise & 81 & 25.6 \\
\hline
\end{tabular}

in that survey, and (c) their responses to the survey would be completely anonymous. Thus, the participants should not hesitate to report their honest thoughts and feelings. Then, after approving the consent form and answering questions, participants received a compensation of $0.30 \$$ in exchange of their participation in the survey.

\section{Measures}

The Behavioral Regulation Exercise Questionnaire-2 (BREQ-2, Markland and Tobin, 2004) was used to measure MPE through the 4-item intrinsic regulation (e.g., "Because I think exercise is fun," $\alpha=0.92$ ), the 3 -item identified regulation (e.g., "Because I value the benefits of exercise," $\alpha=0.81$ ), the 4 -item introjected regulation (e.g., "Because I feel guilty when I don't exercise," $\alpha=0.75$ ), the 4 -item external regulation (e.g., "Because other people say I should," $\alpha=0.85$ ), and the 4 -item amotivation subscales (e.g., "I don't see why I should have to exercise," $\alpha=0.88$ ). A-MPE was assessed through different subscales, such as intrinsic and identified regulations, while C-MPE was assessed through the subscales of introjected regulation and external regulation. Impersonal MPE was assessed through the amotivation subscale. The items of BREQ-2 were scored from 1 ("Not true for me") to 5 ("Very true for me").

The 13-item questionnaire provided by Tangney et al. (2004) was used to assess TSC (e.g., "I am good at resisting temptation;" $\alpha=0.76$ ) on a 7-Lickert scale ranging from "Not at all" ("1") to 7 "Very much so" ("7"). SWB was assessed through two scales: Happiness and vitality. The 8-item Oxford Happiness Questionnaire (OHQ; Hills and Argyle, 2002) was employed to measure happiness (e.g., "I am well satisfied about everything in my life," $\alpha=0.81 ; 1=$ "Strongly disagree," $6=$ "Strongly agree"), while vitality was measured using the 6-item vitality scale of Bostic et al. (2000), which was a revised version of the vitality scale developed by Ryan and Frederick (1997) (e.g., "I feel alive and vital"; $\alpha=0.94 ; 1=$ "Not at all," $7=$ "Very true").

\section{Analysis}

To examine our hypotheses, a two-step analysis was carried out in order to assess the quality of model: Measurement model analysis and structural model analysis. Those assessments were carried out using the PLS (Partial Least Square) structural equation method (XLSTAT-PLS, Addinsoft, version 2016.02.29253). A bootstrapping with 1000 iterations of resampling was conducted.

\section{Measurement Model and Correlation Analyses}

A measurement model includes latent and manifest variables. According to Vinzi et al. (2010), a set of manifest variables can be considered as a latent variable when, at least, one of the following conditions is satisfied: (a) the principal component analysis reveals that the first eigenvalue of the correlation matrix is higher than 1, while the other eigenvalues are smaller; (b) the Cronbach's alpha index (determining the internal consistency) is larger than 0.700; and (c) the Dillon-Goldstein's rho index (determining the composite reliability of the latent variables) is larger 0.700 (Vinzi et al., 2010). According to the selfdetermination theory (e.g., Deci and Ryan, 2008a,b), human functioning can be conceptualized through the concepts of autonomous and controlled motivations, which might both endorse the status of latent variable. As a result, the measurement model considered intrinsic and identified regulations as the manifest variables of the latent variable "A-MPE," while it considered introjected and external regulations as the manifest variables of the latent variable "C-MPE." Moreover, the model gathered the constructs of happiness and vitality to form an index of SWB. Furthermore, based on the latent variables coming from confirmatory factor analysis, non-parametric (Spearman's rho) correlations were carried out.

\section{Structural Model and Mediation Analyses}

A structural model provides standardized path coefficients (estimated through ordinary least squares regressions) that indicated the strength of the causal relationships. Mediation might be shown when the following criteria are satisfied: (a) the direct relationship between independent and dependent variables (excluding the interaction of the mediator) is significant; (b) the mediator establishes significant relationships with the 
independent and dependent variables; and (c) the indirect and total effects (including the interaction of the mediator) are significant. Additionally, the strength of mediation is assessed through variance accounted for (VAF): VAF $=$ (indirect effect/total effect). The VAF values above $80 \%$, between 20 and $80 \%$, or below $20 \%$ indicate that the mediation is full, partial, or non-significant, respectively (Hair et al., 2014). The data were controlled for socio-demography, medical status, and characteristics of exercise as potential confounders (Figure 2).

\section{Estimation of Model Quality}

Two sorts of index were used to assess the quality of measurement and structural models: GoF indexes and the coefficient of determination of the endogenous latent variables, $\mathrm{R}^{2}$. Firstly, different GoF indexes can be distinguished: Absolute GoF (assessing the overall quality of the measurement and structural models), relative GoF (corresponding to a transformation of the absolute GoF), outer model GoF (assessing the quality of the measurement model), and inner model GoF (assessing the quality of the structural model). A GoF index varies between 0 (model rejection) and 1 (model validation). More specifically, the critical value for the relative GoF, outer model GoF, and inner model GoF indexes is 0.900. In other words, a value equal to or higher than that threshold for those indexes is considered as satisfying (e.g., Tenenhaus et al., 2005; Vinzi et al., 2010). In addition, a value of the absolute GoF equal to or higher than $0.010,0.250$, or 0.360 reflects a small, moderate, or large overall quality of the both measurement and structural models (Antioco et al., 2008). Secondly, a structural model can be also assessed through $R^{2}$ (e.g., Henseler et al., 2009). More specifically, the $R^{2}$ values of $0.19,0.33$, and 0.67 are considered weak, moderate, and substantial, respectively (Chin, 1998).

\section{RESULTS}

\section{Factor Analysis and Correlations}

The factor analysis yielded three factors: A-MPE, C-MPE, and SWB (Table 2; Figure 2). Non-parametric correlations revealed that the three types of motivation (i.e., A-MPE, C-MPE, and NO-MPE) were all related to each other ( $\rho$ s $=-0.513$ to 0.511 ; Table 3). A-MPE was negatively related to C-MPE $(\rho=-0.233)$ and NO-MPE $(\rho=-0.513)$, while C-MPE and NO-MPE were

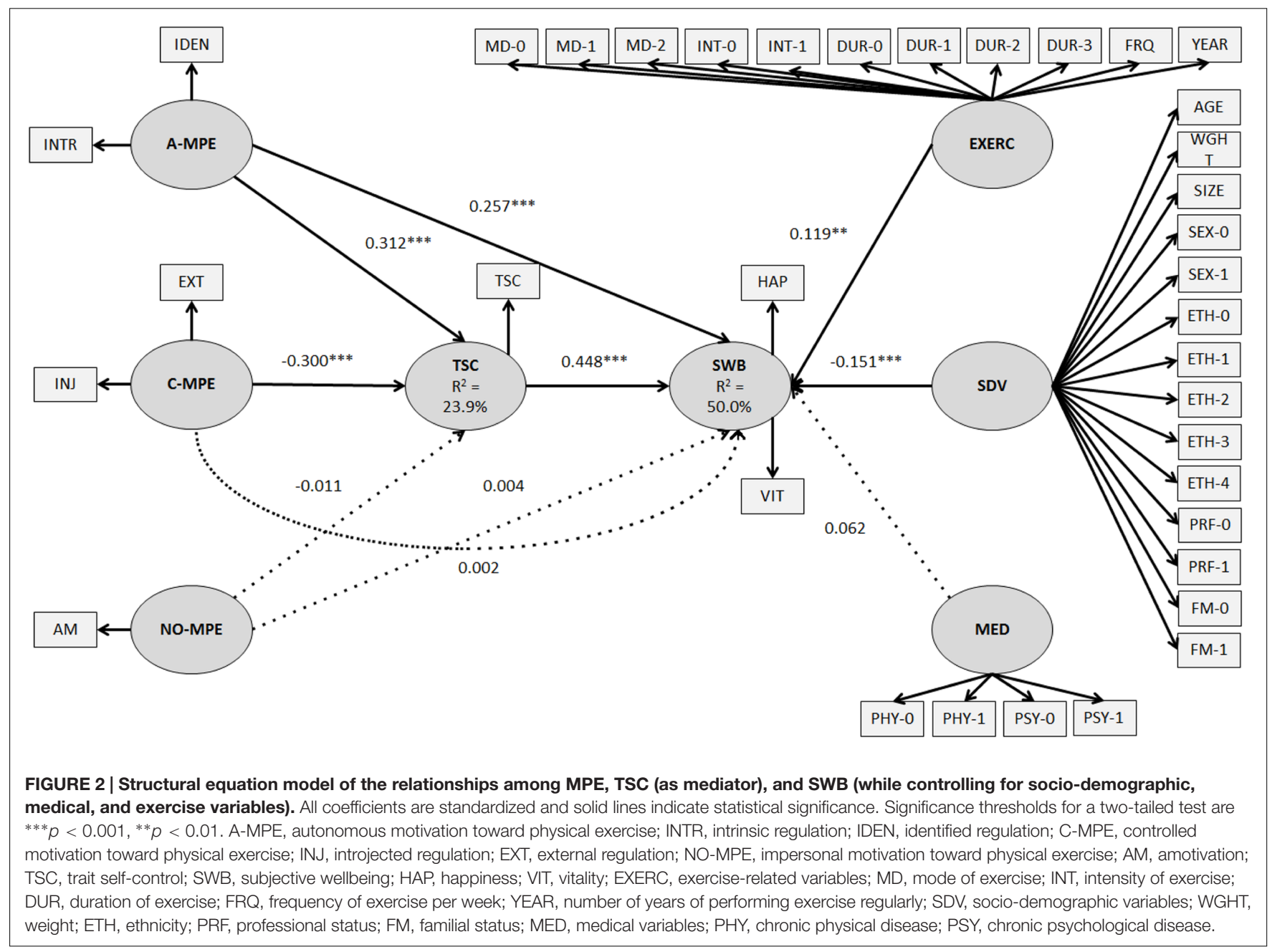


TABLE 2 | Unidimensionality of manifest variables blocks.

\begin{tabular}{lcccc}
\hline LV Name & \# of MVs & Cronbach's $\alpha$ & D.G.'s $\rho$ & PCA eigenvalues \\
\hline A-MPE & 2 & 0.700 & 0.869 & 1.538 \\
& 2 & 0.462 & 0.788 & 0.462 \\
C-MPE & 2 & & & 1.300 \\
& \multirow{2}{*}{2} & 0.866 & 0.937 & 0.700 \\
SWB & & & & 1.764 \\
& & & & 0.236 \\
\hline
\end{tabular}

$L V$, latent variable; MV, manifest variable; D.G.'s $\rho$, Dillon-Goldstein's rho; PCA, principal component analysis; A-MPE, autonomous motivation toward physical exercise; C-MPE, controlled motivation toward physical exercise; SWB, subjective wellbeing.

positively related ( $\rho=0.511$; Table 3 ). Furthermore, A-MPE, TSC, and SWB appeared to be all positively related to each other ( $\rho$ s = 0.382-0.603; Table 3). C-MPE and NO-MPE were both negatively related to TSC and SWB ( $\rho s=-0.426$ to -0.292 ; Table 3).

\section{Structural Equation Model and Mediations}

The $\mathrm{R}^{2}$ value associated with the endogenous latent variables was moderate, being equal to $36.947 \%$ (absolute $\mathrm{GoF}=0.330$; relative $\mathrm{GoF}=0.942$; outer model $\mathrm{GoF}=0.935$; inner model GoF $=1.008$; Table 4; Figure 2). Two significant mediations were found: TSC appeared to mediate the relationships between A-MPE and SWB (partial mediation), and between C-MPE and SWB (full mediation; Table 5; Figure 2). However, TSC did not mediate the relationship between NO-MPE and SWB (Table 5; Figure 2).

\section{DISCUSSION}

The present study utilized the self-determination theory (e.g., Deci and Ryan, 2008a), the control-process theory of selfregulation (e.g., Carver and Scheier, 1998; McCullough and Willoughby, 2009), and the theory of multiple pathways of TSC (e.g., Hagger, 2014) in order to examine how MPE, TSC, and SWB might be interrelated, and whether TSC might mediate the relationships between MPE and SWB.

TABLE 3 | Non-parametric (Spearman's rho) correlations for all latent variables.

\begin{tabular}{lcccc}
\hline Latent variable & $\mathbf{1}$ & $\mathbf{2}$ & $\mathbf{3}$ & $\mathbf{4}$ \\
\hline 1. A-MPE & - & & & \\
2. C-MPE & $-0.233^{* * *}$ & - & & \\
3. NO-MPE & $-0.513^{* * *}$ & $0.511^{* * *}$ & - & - \\
4. TSC & $0.382^{* * *}$ & $-0.426^{* * *}$ & $-0.390^{* * *}$ & - \\
5. SWB & $0.516^{* * *}$ & $-0.292^{* * *}$ & $-0.358^{* * *}$ & $0.603^{* * *}$ \\
\hline
\end{tabular}

The data of all latent variables come from confirmatory factor analysis. ${ }^{* * *} p<0.001$ for a two-tailed test.

A-MPE, autonomous motivation toward physical exercise; C-MPE, controlled motivation toward physical exercise; NO-MPE, no motivation toward physical exercise; TSC, trait self-control; SWB, subjective wellbeing.

\section{Relationships between Motivation toward Physical Exercise, Trait Self-Control, and Subjective Wellbeing}

The analyses revealed that A-MPE was positively related to SWB, whereas C-MPE and NO-MPE were both negatively related to SWB. These results support the predictions of the selfdetermination theory according to which A-MPE (or C-MPE and NO-MPE) may promote (or hinder) wellbeing (Deci and Ryan, 2008a,b). They also support previous studies that showed that autonomous (or controlled and impersonal) forms of MPE were positively associated with positive (or negative) psychological outcomes (e.g., Edmunds et al., 2006; Gillison et al., 2006, 2011; Sebire et al., 2009). According to the self-determination theory, people may deeply experience wellbeing when their social environment supports their innate needs for competence, relatedness, and especially autonomy. By contrast, when the social environment thwarts their need for autonomy, they are more likely to experience a decreased sense of wellbeing or even depression symptoms.

The analyses revealed that A-MPE was positively related to TSC, supporting the results of previous studies that have revealed positive associations between autonomous motivation and indicators of high self-control, such as TSC (Briki et al., 2015), implementation planning (Koestner et al., 2008), and automatic attraction toward helpful goals (Milyavskaya et al., 2015). This result is also compatible with the studies that have shown that autonomous motivation was negatively associated with indicators of low self-control, such as automatic attraction toward temptations and perception of encountering obstacles (Milyavskaya et al., 2015). Finally, our result supports the general view that autonomous activity would improve the effectiveness of self-regulation processes (e.g., goal selection) because such an engagement in the activity would lie in a strong sense of volition and willingness (Carver and Scheier, 1998; Deci and Ryan, 2000). Furthermore, the analyses revealed that C-MPE was negatively related to TSC, running counter most of the studies that have shown independent relationships between controlled motivation and indicators of high self-control (i.e., TSC, implementation planning, automatic attraction toward helpful goals; Koestner et al., 2008; Briki et al., 2015; Milyavskaya et al., 2015). However, our result is consistent with Milyavskaya et al.'s (2015) study that has revealed a positive association between controlled motivation and low self-control (i.e., perception of encountering obstacles). More generally, our result is compatible with the view that controlled activity would lead to a decreased sense of self-regulation because imposed contingencies driving such a psychological functioning would stay away from the self (Carver and Scheier, 1998; Deci and Ryan, 2000). Taken together, our results support the studies that have revealed that autonomous motivation saved more resources and enabled people to perform better on subsequent tasks than controlled motivation (Moller et al., 2006; Muraven et al., 2007, 2008; Muraven, 2008). Furthermore, NO-MPE was negatively associated with TSC, and this result supports the view of the self-determination theory that NO-MPE would be associated with passivity (the opposite of self-control), anxiety, and depression, caused by the 
TABLE 4 | Path estimates of the PLS model.

\begin{tabular}{|c|c|c|c|c|c|c|}
\hline Effects & Path & $\beta$ & SE & $t$-values & $p$-values & $f^{2}$ \\
\hline \multirow[t]{3}{*}{ Direct } & A-MPE $\rightarrow$ SWB & 0.453 & 0.058 & 7.830 & 0.000 & 0.196 \\
\hline & C-MPE $\rightarrow$ SWB & 0.151 & 0.054 & 2.804 & 0.005 & 0.025 \\
\hline & NO-MPE $\rightarrow$ SWB & 0.021 & 0.063 & 0.331 & 0.741 & 0.000 \\
\hline \multirow[t]{7}{*}{ Mediating } & A-MPE $\rightarrow$ TSC & 0.312 & 0.060 & 5.244 & 0.000 & 0.088 \\
\hline & C-MPE $\rightarrow$ TSC & 0.300 & 0.055 & 5.464 & 0.000 & 0.095 \\
\hline & $\mathrm{NO}-\mathrm{MPE} \rightarrow \mathrm{TSC}$ & 0.011 & 0.064 & 0.169 & 0.866 & 0.000 \\
\hline & $\mathrm{TSC} \rightarrow \mathrm{SWB}$ & 0.448 & 0.047 & 9.477 & 0.000 & 0.291 \\
\hline & $\mathrm{A}-\mathrm{MPE} \rightarrow \mathrm{SWB}$ & 0.257 & 0.052 & 4.961 & 0.000 & 0.080 \\
\hline & C-MPE $\rightarrow$ SWB & -0.002 & 0.047 & -0.033 & 0.974 & 0.000 \\
\hline & NO-MPE $\rightarrow$ SWB & 0.004 & 0.053 & 0.082 & 0.935 & 0.000 \\
\hline
\end{tabular}

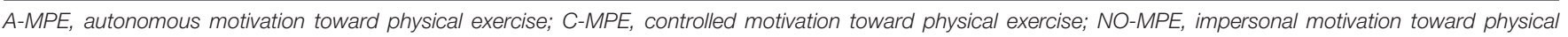
exercise; TSC, trait self-control; SWB, subjective wellbeing.

TABLE 5 | Mediation analysis.

\begin{tabular}{|c|c|c|c|c|c|c|c|c|c|}
\hline Effects & Path & Mediator & IV $\rightarrow$ Mediator & Mediator $\rightarrow$ DV & $\begin{array}{l}\text { Direct } \\
\text { effect }\end{array}$ & $\begin{array}{l}\text { Indirect } \\
\text { effect }\end{array}$ & $\begin{array}{l}\text { Total } \\
\text { effect }\end{array}$ & VAF & $\begin{array}{c}\text { Mediation } \\
\text { strength }\end{array}$ \\
\hline \multirow{3}{*}{$\begin{array}{l}\text { Direct without } \\
\text { mediator }\end{array}$} & A-MPE $\rightarrow$ SWB & N/A & $\mathrm{N} / \mathrm{A}$ & $\mathrm{N} / \mathrm{A}$ & $0.453^{* * *}$ & $\mathrm{~N} / \mathrm{A}$ & $\mathrm{N} / \mathrm{A}$ & $\mathrm{N} / \mathrm{A}$ & $\mathrm{N} / \mathrm{A}$ \\
\hline & C-MPE $\rightarrow$ SWB & $\mathrm{N} / \mathrm{A}$ & N/A & $\mathrm{N} / \mathrm{A}$ & $0.151^{* *}$ & $\mathrm{~N} / \mathrm{A}$ & $\mathrm{N} / \mathrm{A}$ & $\mathrm{N} / \mathrm{A}$ & $\mathrm{N} / \mathrm{A}$ \\
\hline & NO-MPE $\rightarrow$ SWB & N/A & $\mathrm{N} / \mathrm{A}$ & $\mathrm{N} / \mathrm{A}$ & 0.021 & N/A & N/A & $\mathrm{N} / \mathrm{A}$ & $\mathrm{N} / \mathrm{A}$ \\
\hline \multirow{3}{*}{$\begin{array}{l}\text { Indirect with } \\
\text { mediator }\end{array}$} & A-MPE $\rightarrow$ SWB & TSC & $0.312^{* * *}$ & $0.448^{* * *}$ & $0.257^{* * *}$ & $0.140 * * *$ & $0.396 * * *$ & $35.2 \%$ & Partial \\
\hline & C-MPE $\rightarrow$ SWB & TSC & $-0.300 * * *$ & & -0.002 & $0.134^{* * *}$ & $0.133^{*}$ & $101.2 \%$ & Full \\
\hline & NO-MPE $\rightarrow$ SWB & TSC & -0.011 & & 0.004 & 0.005 & 0.009 & N/A & N/A \\
\hline
\end{tabular}

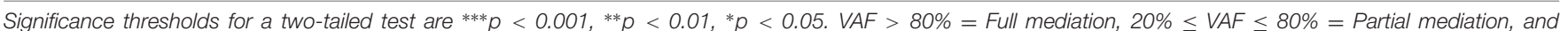
$V A F<20 \%=$ No mediation (none).

IV, independent variable; DV, dependent variable; VAF, variance accounted for; N/A, not applicable; A-MPE, autonomous motivation toward physical exercise; C-MPE, controlled motivation toward physical exercise; NO-MPE, impersonal motivation toward physical exercise; TSC, trait self-control; SWB, subjective wellbeing.

dissatisfaction of the three innate needs (e.g., Deci and Ryan, 2008a,b).

The analyses revealed that TSC was positively related to SWB, supporting the results of previous studies that have reported positive associations between self-control, goal attainment, and satisfaction (e.g., Rhodes et al., 2002; De Ridder et al., 2012; Cheung et al., 2014; Hofmann et al., 2014; Briki et al., 2015). More specifically, research has found that TSC: (a) increased positive affect and SWB (e.g., De Ridder et al., 2012; Hofmann et al., 2014; Briki et al., 2015); (b) inhibited conflict among goals and goal-disruptive impulses (e.g., Hagger, 2014; Hofmann et al., 2014); and (c) stimulated and inhibited helpful (e.g., promotion focus) and unhelpful (e.g., prevention focus) plans for action, respectively (e.g., Cheung et al., 2014; Hagger, 2014). Taken together, those studies suggest the view that TSC would develop a strong sense of SWB by optimizing selfregulation processes and increasing the frequency of positive emotions.

\section{The Mediating Effects of Trait-Self-Control}

The analyses revealed two significant mediations. Firstly, TSC appeared to mediate partially the relationship between A-MPE and SWB, supporting the results of Briki et al.'s (2015) study showing a partial mediation of TSC in the relationship between autonomous religious motivation and SWB. More specifically, our result indicates that A-MPE would increase directly SWB, supporting the view that the satisfaction of people's innate needs would be, by nature, a deep source of wellbeing (e.g., Deci and Ryan, 2008a,b). Our result also indicates that A-MPE would increase indirectly SWB via TSC. This suggests that A-MPE would improve self-regulation processes, thereby leading to facilitate the movement toward the desired goals and to increase the frequency of positive experiences (Koestner et al., 2008; Hofmann et al., 2014; Milyavskaya et al., 2015). Secondly, TSC appeared to mediate fully the relationship between $\mathrm{C}-\mathrm{MPE}$ and $\mathrm{SWB}$, suggesting that $\mathrm{C}-\mathrm{MPE}$ would influence SWB only through TSC. In other words, C-MPE would decrease SWB by decreasing the effectiveness of self-regulation processes while pursuing goals (e.g., Deci and Ryan, 2000). Our result runs counter the results of Briki et al.'s (2015) study showing that TSC did not mediate the relationship between controlled religious motivation and SWB, but is compatible with the study of Milyavskaya et al. (2015) showing that self-control mediated the relationship between controlled motivation and goal process. Such inconsistencies should incite psychologists to pay more attention to the link between controlled forms of motivation and the mechanisms of 
self-control. Furthermore, TSC did not mediate the relationship between NO-MPE and SWB, and NO-MPE did not predict TSC and SWB. These results suggest that NO-MPE would not activate any regulatory processes. Indeed, NO-MPE reflects a psychological state characterized by the absence of intentionality to behave in the exercise context, thus standing in contrast to A-MPE and C-MPE. More generally, this study supports the views that TSC reflects an effective mediating variable to account for the relationship between commitment to an activity and wellbeing (McCullough and Willoughby, 2009), and that TSC corresponds to a crucial determinant of psychological health (e.g., Tangney et al., 2004).

\section{CONCLUSION AND PERSPECTIVES}

The results of the present study are the first to support the hypothesis that MPE can influence SWB through TSC. However, this study is not without limitations. Chief among them is its correlational nature, and thus further studies should use stronger causal tests. To do so, experimental studies should examine the effects of stimuli related to A-MPE (e.g., autonomysupportive context in exercise settings) and C-MPE (e.g., controlling context in exercise settings) on self-control and SWB. Furthermore, by considering motivation, self-control, and feelings as dynamical processes, time-based designs should be used to examine how MPE, TSC, and SWB may fluctuate over time. In that regard, the use of the ambulatory assessment

\section{REFERENCES}

Antioco, M., Moenaert, R., Feinberg, R., and Wetzels, M. (2008). Integrating service and design: the influences of organizational and communication factors on relative product and service characteristics. J. Acad. Market. Sci. 36, 501-521. doi: 10.1007/s11747-008-0097-x

Baumeister, R. F., and Heatherton, T. F. (1996). Self-regulation failure: an overview. Psychol. Inq. 7, 1-15. doi: 10.1207/s15327965pli0701_1

Baumeister, R. F., Vohs, K. D., and Tice, D. M. (2007). The strength model of self-control. Cur. Dir. Psychol. Sci. 16, 351-355. doi: 10.1111/j.14678721.2007.00534.x

Biddle, S. J. H., and Asare, M. (2012). Physical activity and mental health in children and adolescents: a review of reviews. Br. J. Sports Med. 45, 886-895. doi: 10.1136/bjsports-2011-090185

Bostic, T. J., McGartland-Rubio, D., and Hood, M. (2000). A validation of the subjective vitality scale using structural equation modeling. Soc. Indic. Res. 52, 313-324. doi: 10.1023/A:1007136110218

Briki, W., Aloui, A., Bragazzi, N. L., Chaouachi, A., Patrick, T., and Chamari, K. (2015). Trait self-control, identified-introjected religiosity and health-relatedfeelings in healthy Muslims: a structural equation model analysis. PLoS ONE 10:e0126193. doi: 10.1371/journal.pone.0126193

Carver, C. S., and Scheier, M. F. (1990). Origins and functions of positive and negative affect: a control-process view. Psychol. Rev. 97, 19-35. doi: 10.1037/0033-295X.97.1.19

Carver, C. S., and Scheier, M. F. (1998). On the Self-Regulation of Behavior. New York, NY: Cambridge University Press.

Cheung, T. L. T., Gillebaart, M., Kroese, F., and De Ridder, D. (2014). Why are people with high self-control happier? The effect of trait self-control on happiness as mediated by regulatory focus. Front. Psychol. 5:722. doi: 10.3389/fpsyg.2014.00722

Chin, W. W. (1998). "The partial least squares approach for structural equation modeling," in Modern Methods for Business Research, ed. G. A. Marcoulides (London: Lawrence Erlbaum Associates), 236-295. methodology (i.e., computerized devices designed to collect selfreported, physiological, and behavioral data in natural contexts) might be helpful to collect data over time within natural contexts (e.g., Kanning et al., 2012). Importantly, such research directions should shed the light on the mediating role of self-control in the MPE-SWB relationships. From an applied standpoint, in order to promote the development of SWB in exercisers, exercise instructors should promote the development of A-MPE since A-MPE appeared to predict SWB (directly as well as indirectly through TSC). To do so, exercise instructors should enhance exercisers' perceptions of autonomy by offering them the opportunity of choice, encouraging them to explore new tasks and techniques, listening to them, limiting controlling self-talk, etc. (Standage and Ryan, 2012). In addition, exercise instructors should always associate exercise with the notion of pleasure.

\section{AUTHOR CONTRIBUTIONS}

WB conceived the study, collected and analysed the data, and wrote and revised the article.

\section{ACKNOWLEDGMENT}

The author wishes to thank the volunteer participants for their valuable time and contribution, and Chiraz Agrebi for rereading that manuscript.

De Neve, J.-E., Diener, E., Tay, L., and Xuereb, C. (2013). “The objective benefits of subjective well-being," in World Happiness Report, Vol. 2, eds J. F. Helliwell, R. Layard, and J. Sachs (New York, NY: UN Sustainable Network Development Solutions Network), 54-79.

De Ridder, D. T. D., Lensvelt-Mulders, G., Finkenauer, C., Stok, F. M., and Baumeister, R. F. (2012). Taking stock of self-control: a meta-analysis of how trait self-control relates to a wide range of behaviors. Pers. Soc. Psychol. Rev. 16, 76-99. doi: 10.1177/1088868311418749

Deci, E. L., and Ryan, R. M. (1985). Intrinsic Motivation and Self-Determination in Human Behavior. New York: Plenum.

Deci, E. L., and Ryan, R. M. (1987). The support of autonomy and the control of behavior. J. Pers. Soc. Psychol. 53, 1024-1037. doi: 10.1037/0022-3514.53.6.1024

Deci, E. L., and Ryan, R. M. (2000). The "what" and "why" of goal pursuits: human needs and the self-determination of behavior. Psychol. Inq. 11, 227-268. doi: 10.1207/S15327965PLI1104_01

Deci, E. L., and Ryan, R. M. (2008a). Facilitating optimal motivation and psychological well-being across life's domains. Can. Psychol. 49, 14-23. doi: 10.1037/0708-5591.49.3.262

Deci, E. L., and Ryan, R. M. (2008b). Self-determination theory: a macrotheory of human motivation, development, and health. Can. Psychol. 49, 182-185. doi: $10.1037 / \mathrm{a} 0012801$

Diener, E. (2000). Subjective well-being. The science of happiness and a proposal for a national index. Am. Psychol. 55, 34-43. doi: 10.1037/0003-066X. 55.1 .34

Diener, E., Oishi, S., and Lucas, R. S. (2015). National accounts of subjective well-being. Am. Psychol. 55, 34-43. doi: 10.1037/a0038899

Edmunds, J., Ntoumanis, N., and Duda, J. L. (2006). A test of self-determination theory in the exercise domain. J. Appl. Soc. Psychol. 36, 2240-2265. doi: 10.1111/j.0021-9029.2006.00102.x

Gillison, F., Standage, M., and Skevington, S. M. (2006). Relationships among adolescents' weight perceptions, exercise goals, exercise motivation, quality of life and leisure-time exercise behaviour: a self-determination theory approach. Health Educ. Res. 21, 836-847. doi: 10.1093/her/cyl139 
Gillison, F., Standage, M., and Skevington, S. M. (2011). Motivation and bodyrelated factors as discriminators of change in adolescents' exercise behavior profiles. J. Adolesc. Health 48, 44-51. doi: 10.1016/j.jadohealth.2010.05.006

Hagger, M. S. (2013). The multiple pathways by which self-control predicts behavior. Front. Psychol. 4:848. doi: 10.3389/fpsyg.2013.00849

Hagger, M. S. (2014). The multiple pathways by which trait self-control predicts health behavior. Ann. Behav. Med. 48, 282-283. doi: 10.1007/s12160-0149631-x

Hair, J. F., Hult, G. T. M., Ringle, C. M., and Sarstedt, M. (2014). A Primer on Partial Least Squares Structural Equation Modeling. Thousand Oaks, CA: Sage.

Henseler, J., Ringle, C. M., and Sinkovics, R. R. (2009). "The use of partial least squares path modeling in international marketing," in Advances in International Marketing, eds R. R. Sinkovics and P. N. Ghauri (Bingley: Emerald), 277-320.

Hills, P., and Argyle, M. (2002). The Oxford Happiness Questionnaire: a compact scale for the measurement of psychological well-being. Pers. Individ. Dif. 33, 1073-1082. doi: 10.1016/S0191-8869(01)00213-6

Hofmann, W., Luhmann, M., Fisher, R. R., Vohs, K. D., and Baumeister, R. F. (2014). Yes, but are they happy? Effects of trait self-control on affective well-being and life satisfaction. J. Pers. 82, 265-277. doi: 10.1111/jopy. 12050

Hofmann, W., Vohs, K. D., and Baumeister, R. F. (2012). What people desire, feel conflicted about, and try to resist in everyday life. Psychol. Sci. 23, 582-588. doi: $10.1177 / 0956797612437426$

Kanning, M., Ebner-Priemer, U., and Brand, R. (2012). Autonomous regulation mode moderates the effect of actual physical activity on affective states: an ambulant assessment approach to the role of self-determination. J. Sport Exerc. Psychol. 34, 260-269. doi: 10.1123/jsep.34.2.260

Koestner, R., Otis, N., Powers, T. A., Pelletier, L., and Gagnon, H. (2008). Autonomous motivation, controlled motivation, and goal progress. J. Pers. 76, 1201-1230. doi: 10.1111/j.1467-6494.2008.00519.x

Lopez, R. B., Milyavskaya, M., Hofmann, W., and Heatherton, T. F. (2016). Motivational and neural correlates of self-control of eating: a combined neuroimaging and experience sampling study in dieting female college students. Appetite 103, 192-199. doi: 10.1016/j.appet.2016.03.027

Markland, D., and Tobin, V. (2004). A modification to the Behavioural Regulation in Exercise Questionnaire to include an assessment of amotivation. J. Sport Exerc. Psychol. 26, 191-196. doi: 10.1123/jsep.26.2.191

McCullough, M. E., and Willoughby, B. L. B. (2009). Religion, self-regulation, and self-control: associations, explanations, and implications. Psychol. Bull. 135, 69-93. doi: 10.1037/a0014213

Melzer, K., Kayser, B., and Pichard, C. (2004). Physical activity: the health benefits outweigh the risks. Curr. Opin. Clin. Nutr. Metab. Care 7, 641-647. doi: 10.1097/00075197-200411000-00009

Meyers, J. (2008). The health benefits and economics of physical activity. Curr. Sports Med. Rep. 7, 314-316. doi: 10.1249/JSR.0b013e31818ee179

Milyavskaya, M., Inzlicht, M., Hope, N., and Koestner, R. (2015). Saying "No" to temptation: "want-to" motivation improves self-regulation by reducing temptation rather than by increasing self-control. J. Pers. Soc. Psychol. 109, 677-693. doi: 10.1037/pspp0000045

Moller, A. C., Deci, E. L., and Ryan, R. M. (2006). Choice and ego-depletion: the moderating role of autonomy. Pers. Soc. Psycho. Bull. 32, 1024-1036. doi: $10.1177 / 0146167206288008$

Muraven, M. (2008). Autonomous self-control is less depleting. J. Res. Pers. 42, 763-770. doi: 10.1016/j.jrp.2007.08.002

Muraven, M., Gagné, M., and Rosman, H. (2008). Helpful self-control: autonomy support, vitality, and depletion. J. Exp. Soc. Psychol. 44, 573-585. doi: 10.1016/j.jesp.2007.10.008

Muraven, M., Rosman, H., and Gagné, M. (2007). Lack of autonomy and selfcontrol: performance contingent rewards lead to greater depletion. Mot. Emot. 31, 322-330. doi: 10.1007/s11031-007-9073-x
Peterson, C., and Park, N. (2003). Positive psychology as the evenhanded positive psychologist views it. Psychol. Inq. 14, 141-146.

Peterson, C., and Seligman, M. E. P. (2004). Character Strengths and Virtues: A Handbook and Classification. Washington, DC: American Psychological Association.

Puetz, T. W., O’Connor, P. J., and Dishman, R. K. (2006). Effects of chronic exercise on feelings of energy and fatigue: a quantitative synthesis. Psychol. Bull. 132, 866-876. doi: 10.1037/0033-2909.132.6.866

Rhodes, R. E., Courneya, K. S., and Hayduk, L. A. (2002). Does personality moderate the theory of planned behavior in the exercise domain? J. Sport Exerc. Psychol. 24, 120-132. doi: 10.5993/AJHB.39.1.15

Ryan, R. M., and Frederick, C. (1997). On energy, personality, and health: subjective vitality as a dynamic reflection of well-being. J. Pers. 65, 529-565. doi: 10.1111/j.1467-6494.1997.tb00326.x

Scully, D., Kremer, J., Meade, M. M., Graham, R., and Dudgeon, K. (1998). Physical exercise and psychological well-being: a critical review. Br. J. Sports Med. 32, 111-120. doi: 10.1136/bjsm.32.2.111

Sebire, S. J., Standage, M., and Vansteenkiste, M. (2009). Examining intrinsic versus extrinsic exercise goals: cognitive, affective, and behavioral outcomes. J. Sport Exerc. Psychol. 31, 189-210. doi: 10.1123/jsep.31.2.189

Sjögren, T., Nissinen, K. J., Järvenpää, S. K., Ojanen, M. T., Vanharanta, H., and Mälkiä, E. A. (2006). Effects of a physical exercise intervention on subjective physical well-being, psychosocial functioning and general well-being among office workers: a cluster randomized-controlled cross-over design. Scand. J. Med. Sci. Sports 16, 381-390. doi: 10.1111/j.1600-0838.2005.00516.x

Standage, M., and Ryan, R. M. (2012). "Self-determination theory and exercise motivation: facilitating self-regulatory processes to support and maintain health and well-being," in Advances in Motivation in Sport and Exercise, 3rd Edn, eds G. C. Roberts and D. C. Treasure (Champaign, IL: Human Kinetics), 233-270.

Stroebe, W., Koningsbruggen, M., Papies, E. K., and Aarts, H. (2013). Why most dieters fail but some succeed: a goal conflict model of eating behavior. Psychol. Rev. 120, 110-138. doi: 10.1037/a0030849

Tangney, J. P., Baumeister, R. F., and Boone, A. L. (2004). High self-control predicts good adjustment, less pathology, better grades, and interpersonal success. J. Pers. 72, 271-322. doi: 10.1111/j.0022-3506.2004.00263.x

Tenenhaus, M., Esposito, V. V., Chatelin, Y.-M., and Lauro, C. (2005). PLS path modeling. Comput. Stat. Data Anal. 48, 159-205. doi: 10.1016/j.csda.2004.03.005

Thøgersen-Ntoumani, C., and Ntoumanis, N. (2006). The role of selfdetermined motivation to the understanding of exercise-related behaviours, cognitions and physical self-evaluations. J. Sports Sci. 24, 393-404. doi: 10.1080/02640410500131670

Vinzi, V. E., Trinchera, L., and Amato, S. (2010). "PLS Path Modeling: from foundations to recent developments and open issues for model assessment and improvement," in Handbook of Partial Least Squares: Concepts, Methods and Applications in Marketing and Related Fields, eds V. E. Vinzi, W. W. Chin, J. Henseler, and H. Wang (Berlin: Springer), 47-82.

Weinstein, N., Deci, E. L., and Ryan, R. M. (2011). Motivational determinants of integrating positive and negative past identities. J. Pers. Soc. Psychol. 100, 527-544. doi: 10.1037/a0022150

Conflict of Interest Statement: The author declares that the research was conducted in the absence of any commercial or financial relationships that could be construed as a potential conflict of interest.

Copyright (c) 2016 Briki. This is an open-access article distributed under the terms of the Creative Commons Attribution License (CC BY). The use, distribution or reproduction in other forums is permitted, provided the original author(s) or licensor are credited and that the original publication in this journal is cited, in accordance with accepted academic practice. No use, distribution or reproduction is permitted which does not comply with these terms. 